\title{
POLÍTICAS PÚBLICAS DE DIREITO À EDUCAÇÃO PARA OS IDOSOS EM INTERNAÇÃO
}

\author{
POLITICAS PUBLICAS DE DERECHO A LA EDUCACIÓN PARA LOS \\ ANCIANOS INTERNOS
}

PUBLIC POLICIES OF RIGHT TO EDUCATION FOR ELDERLY PATIENTS

\author{
Hamilton de Oliveira TELLES JÚNIOR ${ }^{1}$ \\ Ivone PANHOCA ${ }^{2}$ \\ Bárbara Lucchesi RAMACCIOTTI ${ }^{3}$ \\ Rosália Maria Netto PRADOS ${ }^{4}$
}

RESUMO: As pessoas estão vivendo mais. A população vem passando por grandes transformações, tanto sociais como tecnológicas, que apontam para a necessidade de processos educacionais específicos para pessoas idosas. O idoso tende a ser apartado socialmente, com prejuízos para sua saúde e, consequentemente, sua qualidade de vida. Este estudo, de abordagem qualitativa, tem como objetivo descrever e analisar as políticas públicas aplicáveis à educação, para o idoso internado em hospitais ou em instituições, com base no modelo de análise de políticas públicas, expresso por Di Giovanni, em que se verificam os atores envolvidos nessas políticas e seus interesses afins. Como possível meio para consecução de um programa dirigido à educação de idosos, evidencia-se a possibilidade da inclusão social do idoso e o uso de programas de educação, com iniciativa do terceiro setor, que no âmbito da educação não formal traz grandes transformações para a sociedade no que se refere ao exercício da cidadania.

PALAVRAS-CHAVE: Envelhecimento. Analfabetismo. Inclusão. Classe hospitalar. Educação não formal.

RESUMEN: La gente está viviendo más. La población viene pasando por grandes transformaciones, tanto sociales como tecnológicas, que apuntan a la necesidad de procesos educativos específicos para personas mayores. El anciano tiende a ser apartado socialmente, con perjuicios para su salud y, consecuentemente, su calidad de vida. Este

\footnotetext{
${ }^{1}$ Universidade de Mogi das Cruzes (UMC) - Mogi das Cruzes - SP - Brasil. Mestrando em Políticas Públicas. E-mail: hamiltonrute@gmail.com

${ }^{2}$ Universidade de Mogi das Cruzes (UMC) - Mogi das Cruzes - SP - Brasil. Departamento de PósGraduação em Políticas Públicas. Professora pesquisadora na linha de Políticas Públicas de Saúde e qualidade de vida. E-mail: i.panhoca@terra.com.br

${ }^{3}$ Universidade de Mogi das Cruzes (UMC) - Mogi das Cruzes - SP - Brasil. Departamento de PósGraduação em Políticas Públicas. Professora pesquisadora na linha de Políticas Culturais, Diversidade e Cidadania. E-mail: barb.lucrama@hotmail.com

${ }^{4}$ Universidade de Mogi das Cruzes (UMC) - Mogi das Cruzes - SP - Brasil. Departamento de PósGraduação em Políticas Públicas. Professora pesquisadora na linha de Políticas Culturais, Diversidade e Cidadania. E-mail: rosalia.prados@gmail.com
} 
estudio, de abordaje cualitativo, tiene como objetivo describir y analizar las políticas públicas aplicables a la educación, para el anciano internado en hospitales o en instituciones, con base en el modelo de análisis de políticas públicas, expresado por Di Giovanni, en el que se verifican los actores involucrados en esas políticas y sus intereses afines. Como posible medio para la consecución de un programa dirigido a la educación de ancianos, se evidencia la posibilidad de la inclusión social del anciano y el uso de programas de educación, con iniciativa del tercer sector, que en el ámbito de la educación no formal trae grandes transformaciones para la educación en la sociedad en lo que se refiere al ejercicio de la ciudadanía.

PALABRAS-CLAVE: Envejecimiento. Analfabetismo. Inclusión. Clase hospitalaria. Educación no formal.

ABSTRACT: The people are living more. The population is going by great transformations, so much social as technological, that point to the need of specific education processes for senior people. The seniors tend to be separated socially, with damages for his/her health and, consequently, his/her life quality. This study, of qualitative approach, has as objective to describe the public politics for the senior's education interned in hospitals or institutions and to analyze the applicable Public Politics to the education based an express analysis model by Di Giovanni, where there are the actors of this public policy and its related interests. How possible middle for attainment of a program driven to the seniors' education is evidenced in the inclusion possibility in the hospital class and the possibility of the use of education programs for youths and adults, with the initiative of third sector, that in the extent of the education no formal he/she brings great transformations for society and education for the senior.

KEYWORDS: Aging. Illiteracy. Inclusion. Hospital class. Non-formal education.

\section{Introdução}

Com o avanço da ciência, o mundo passa por uma transição demográfica que é um processo caracterizado principalmente pela longevidade de seus cidadãos, a estrutura etária e o tamanho da população. A dinâmica social sofre a influência de novos paradigmas que emergem do contexto demográfico, principalmente com o aumento da população de idosos. Novos desafios surgem na sociedade devido a este envelhecimento. "O paradigma da longevidade com qualidade de vida, antes de tudo, pressupõe a superação de estigmas, preconceitos e a concepção de que o envelhecimento estaria associado ao declínio, à incapacidade e à morte" (SOARES; ISTOE, 2015, p.2).

Entende-se que a educação ocupa papel fundamental para o envelhecimento saudável, pois favorece a formação crítica, para que o indivíduo possa manter-se ativo e 
em condições de maior inserção social, de exigir mais respeito, dignidade e seus direitos. A educação envolve uma sensibilização cultural e de comportamento e é um agente da ação que transforma. A educação é um direito elementar de todo ser humano, independentemente de sua idade e o fato de ter sido alfabetizado durante a sua trajetória de vida, não se justifica a negação de uma educação de qualidade. (SOARES; ISTOE, 2015)

A Lei 10.741, Estatuto do Idoso, de 1 de outubro de 2003, regula os direitos das pessoas com idade igual ou superior a 60 anos. No seu Art. $2^{\circ}$, assegura que o idoso goza de todos os direitos fundamentais inerentes à pessoa humana, assegurando-lhe todas as oportunidades e facilidades para preservação de sua saúde física, mental, seu aperfeiçoamento moral, intelectual, espiritual e social, em condições de liberdade e dignidade. E nos seus Artigos 3.', 20 e 21, determina ser obrigação da família, da comunidade, da sociedade e do Poder Público assegurar ao idoso a efetivação, entre outros aspectos, do direito à educação e à cultura, respeitando sua peculiar condição de idade, através da criação de oportunidades de acesso do idoso à educação, adequando currículos, metodologias e material didático aos programas educacionais a ele destinados (BRASIL, 2003).

Pensar no direito à educação para o idoso em internação, é pensar em quebrar com preconceitos sociais e a Educação apresenta-se como uma forma de superação aos obstáculos que mantêm o idoso distante do universo atualizado do conhecimento. Segundo Freire (1994) é preciso levar a educação a todos os lugares, em todas as situações, pois ela liberta, e precisamos romper com o pensamento de que ser idoso é a espera do fim.

Este artigo analisa as políticas públicas aplicáveis à educação, com base no modelo de análise proposto por Di Giovanni (2009), com o objetivo de descrever a possibilidade de oferecer educação para idosos em internação.

Ao se observar as situações sociais, consideradas problemáticas, podemos entender as políticas públicas. É preciso compreender a planificação consolidada nos aparelhos de Estado, seja do ponto de vista técnico de gestão, seja do ponto de vista político, como uma estrutura republicana, com a existência de poderes independentes, vigência de direitos humanos e cidadania. Nesse contexto, é necessário considerar alguma capacidade coletiva de exercício pleno da cidadania e uma cultura compatível a esses princípios. 
Dentro de um conceito evolutivo da Ciência Política, segundo Di Giovanni (2009) temos um acervo que inclui: construções de tipologias, inovações conceituais, identificação de estruturas, estabelecimento de ciclos, identificação de aspectos normativos e pluralidade de atores. Toda política pública baseia-se em quatro diferentes ângulos de observação: estrutura formal, estrutura substantiva, estrutura material e estrutura simbólica.

A presente análise amplia a percepção das possibilidades educacionais no ambiente institucional e hospitalar. Proporciona, assim, contribuições para a discussão de mais uma forma de melhorar a qualidade de vida do idoso e, para a ciência, apresenta novas possibilidades de estudos.

\section{Inclusão}

A inclusão educacional constitui uma prática recente no processo de universalização da educação. Muito além de se inserir na escola, ela se evidencia em princípios que objetivam à aceitação das diferenças individuais, à valorização do conhecimento pessoal, à aprendizagem através do respeito e da convivência dentro da diversidade humana (BRASIL, 2011). A Educação Inclusiva sustenta que as escolas, enquanto comunidades educativas, devem atender às necessidades de todos indistintamente, independentemente de ter ou não deficiência (MANTOAN, 2015). Nesse contexto, a escola deve favorecer a todos de forma livre, para que se reconheça no outro os mesmos direitos que se exige para si.

Pode-se entender, que nesta concepção o conceito de inclusão se expande para aqueles que, de certa forma, possuem dificuldades. Conforme Mantoan $(2015$, p. 28) "Na perspectiva da inclusão, o sistema de ensino é provocado, desestabilizado, pois o objetivo não é excluir ninguém [...]". A inclusão não pede a adaptação, como se o incluído fosse um transtorno aos outros integrantes, é preciso perceber que a maneira com que se conduz a educação ainda atua sobre modernas ideias utilizando-se as velhas práticas. Deste modo, segundo Mantoan (2015), a inclusão total e irrestrita é uma oportunidade para revertermos essas concepções, dentro e fora das escolas, quebrando paradigmas entre normais e incluídos.

Sendo assim, fica explícito na Meta 9, do Plano Nacional de Educação, PNE, “elevar a taxa de alfabetização da população [...] e até o final da vigência deste PNE, 
erradicar o analfabetismo [...]" (BRASIL, 2014). E a educação inclusiva abrange a todos, acometidos de alguma doença ou impossibilidade, logo, o idoso que se encontra em situação de internação, seja em hospital ou instituição, é um sujeito fragilizado, que muitas vezes é ignorado em seu direito por ser desconhecedor deste.

A política pública, como área de conhecimento, surge nos Estados Unidos de maneira inesperada, diferente da europeia, que surge de um desdobramento de trabalhos em teorias explicativas do papel do Estado. A disciplina de política pública nos Estados Unidos, segundo Souza (2006, p. 22) "nasce como subárea da ciência política, abre o terceiro grande caminho trilhado pela ciência política norte-americana no que se refere ao estudo do mundo público [...] como um ramo da ciência política para entender como e por que os governos optam por determinadas ações”. Elas são um conjunto de decisões, planos, metas e ações governamentais voltados para a resolução de problemas de interesse público, específicos ou não, como a construção de uma escola, uma ponte, transporte coletivo, melhores condições na saúde pública, educação etc (SOUZA, 2006). As políticas públicas consideradas de proteção social têm em seu princípio diminuir as diferenças sociais, distribuindo benefícios e reduzindo desigualdades estruturais causadas pelo desenvolvimento socioeconômico.

Somente por meio de grupos organizados, a sociedade pode apelar aos seus representantes no poder legislativo e executivo, para que atendam às solicitações de seus representados. O debate entre os diversos grupos proporciona a democracia, assegura e permite que os mais diversos grupos atuem em um jogo no qual a democracia se fortalece ainda mais.

Nesse sentido, Carvalho (2009) ressalta que a liberdade de associação e a presença de grupos de interesse e de pressão são importantes para o fortalecimento da democracia, mas a existência destes grupos organizados não é garantia de atendimento de suas expectativas, pois o processo das políticas públicas compreende uma seleção das prioridades visando responder às demandas de necessidades dos segmentos sociais mais vulneráveis da sociedade, o que certamente nunca abrange todas as questões. Assim, é preciso que as reivindicações ganhem força através de mobilizações sociais e chamem a atenção da mídia, aumentando o impacto junto às autoridades (PERUZZO, 2015).

\section{Modelo de estruturas elementares das políticas públicas}


Segundo Di Giovanni (2009), existem duas conduções no processo de estudo em ciências da cultura: a construção de tipos conceituais e, a construção de tipos históricos. A análise deve ser feita com a observação histórica e a construção teórica, pois através da observação histórica das políticas públicas possibilita-se a identificação de elementos invariantes, únicos. A estrutura formal, conforme Di Giovani (2009), é composta por três elementos básicos: a teoria, a prática e os resultados. A teoria de uma política pública é entendida como o conjunto de propostas de origem diversas que dá sustentação às práticas da intervenção, em busca de um determinado resultado.

Para se entender o direito à educação, precisamos relacionar o conjunto de normas, princípios, leis e regulamentos sobre o assunto, que compõe o "Tema” (DI GIOVANNI, 2009). Neste sentido, temos o conjunto de Leis que disciplinam as relações entre os atores na arena das políticas públicas no processo de ensino aprendizagem.

A Constituição Federal (BRASIL, 1988) expressa em seu Art. 6ª a educação como um Direito Social, no Art. 205, que é um direito de todos e dever do Estado e da família, será promovida e incentivada com a colaboração da sociedade. Na Lei de Diretrizes e Bases da Educação Nacional no 9394, de 20 de dezembro de 1996, em seu Art. 37, versa que "A educação de jovens e adultos será destinada àqueles que não tiveram acesso ou continuidade de estudos no ensino fundamental e médio na idade própria" (BRASIL, 1996), além de assinalar como uma de suas diretrizes a Inclusão. E com o Plano Nacional de Educação (BRASIL, 2014) que em seu Art. $2^{\circ}$, Inciso I, determina como uma de suas diretrizes "a erradicação do analfabetismo".

Por meio dessas referências legais, além de outras, percebemos a clara proposta do Estado em empreender esforços para que todos tenham acesso à educação, superando os obstáculos, sejam estes quais forem. Nesse sentido, as políticas de inclusão apresentam-se de forma crescente desde a década de 1990 com a Declaração de Salamanca (BRASIL, 1994).

Examinando o Estatuto do Idoso (BRASIL, 2003), podemos citar que o Art. $3^{\circ}$ expressa a obrigação da família, comunidade, sociedade e do Poder Público assegurar ao idoso como prioridade o direito à educação e à dignidade. No Art. $4^{\circ}$, temos que nenhum idoso será objeto de qualquer tipo de negligência, discriminação, violência, crueldade ou opressão. E todo atentado aos seus direitos, neste mesmo artigo, consta no parágrafo $1^{\circ}$, que é dever de todos prevenir a ameaça ou violação aos direitos do idoso. No Art. $9^{\circ}$ apresenta-se a obrigação do Estado de garantir políticas públicas que permitam o envelhecimento com dignidade; e no Art. 10, do referido Estatuto, reforçam-se as 
obrigações do Estado e sociedade, assegurando o respeito aos direitos civis e outros garantidos na legislação brasileira e culminando no capítulo V, nos Art. 20 e 21, respectivamente, está claramente versado "O Idoso tem direito à Educação", "O Poder Público criará oportunidades de acesso à educação" (BRASIL, 2003).

Para as "práticas", Di Giovanni (2009) explica que elas revelam as ações realizadas. Nesse sentido, entende-se que a educação é direito público subjetivo e isso quer dizer que o acesso é obrigatório e deve ser gratuito. Para consecução deste, o governo apresenta várias ações que vão desde programas realizados nos estabelecimentos regulares de ensino a programas de Educação a Distância.

Infere-se, na página da Secretaria de Educação Continuada, Alfabetização, Diversidade e Inclusão, SECADI, em articulação com os sistemas de ensino para implementar políticas educacionais nas áreas de alfabetização, educação de jovens e adultos, educação ambiental, educação em direitos humanos, educação especial, do campo, escolar indígena, quilombola e educação para as relações étnico-raciais, que a educação é para todos. Seu objetivo é contribuir para o desenvolvimento inclusivo dos sistemas de ensino, voltado à valorização das diferenças e da diversidade, à promoção da educação inclusiva, dos direitos humanos e da sustentabilidade socioambiental, visando à efetivação de políticas públicas transversais e intersetoriais.

Assim, buscar e utilizar os espaços existentes para educação, com a simples inclusão do acesso de idosos a estes, já caracteriza a oportunidade de manutenção deste idoso ao mundo do conhecimento, a oportunidade de poder refletir sobre as necessidades contemporâneas, proporcionando a atividade intelectual reintegrando-o como sujeito social ativo e não como alguém que deve primar pela futilidade, pois já ultrapassou a idade considerada útil.

Quanto aos "resultados", Di Giovanni (2009) propõe que se confronte a teoria e a prática para percepção dos resultados alcançados. Entretanto, observa-se, que a área da educação em hospitais e instituições não estão presentes nessas descrições. Não existem documentos disponibilizados, não existem dados oficiais sobre quantas classes hospitalares ou mesmo quantos professores atuam e quantos alunos atendidos, no site da SECADI. Todos estão invisíveis para o poder público.

Para a viabilidade de uma política pública, a questão do financiamento é importante, a estrutura material deve atentar para as condições e os aspectos econômicos de uma política pública, segundo Di Giovanni (2009) devem abranger a exequibilidade e sustentação material. 
As políticas educacionais possuem seu recurso previsto no Orçamento. Encontramos no site do Ministério do Planejamento, Desenvolvimento e Gestão que o orçamento é um documento no qual estão alocadas as receitas arrecadadas e em que estão investidos esses recursos, qual seu destino e, a educação possui seu espaço bem como recursos destinados. Assim, concebe-se que a educação para idosos estaria incluída nas verbas da educação.

Di Giovanni (2009) explica também a necessidade de se entender a estrutura substantiva das políticas públicas que é composta por três elementos: atores, interesses e regras. A relação entre atores, interesses e regras podem ser compreendidas pelo conceito weberiano de ação social. Uma ação é social quando o indivíduo parte de uma intenção ou motivação e estabelece uma comunicação com os outros. Neste caso, deve-se buscar um mínimo de padronização e institucionalização, interesses e regras. Segundo esse entendimento, precisa-se saber quem são os atores e seus papéis na consecução desta pretensa política pública. Esses atores são as pessoas, grupos ou instituições que, de alguma maneira ou forma, participam da formulação, da implementação e dos resultados de uma política (DI GIOVANNI, 2009).

\section{Os atores sociais e seus papéis}

Entender o interesse de cada um dos atores sociais é um meio para se perceber a convergência ou divergência destes. Como primeiro ator social, indicamos os pacientes idosos internados em instituições (organizados ou não), pois uma política pública atende a todos. Entende-se como interesse para este grupo, a qualidade de vida, que segundo Minayo (2000) é uma noção que pertence ao ser humano, pressupõe capacidade de síntese cultural em relação a padrões de bem-estar social, e valores não materiais tais como o amor, liberdade, solidariedade, felicidade etc, portanto, refere-se à satisfação de necessidades elementares da vida humana e dentre elas temos a educação.

Pode-se pensar, também, em formas de oposição à qualidade de vida, como o desemprego, exclusão social e violência. Assim mesmo, sendo um conceito polissêmico, merece a atenção da educação, enquanto promotora de oportunidades de socialização, atualização e reintegração no mercado de trabalho atualizando o conhecimento adquirido durante a vida às novas tecnologias. Bartholo et. al. (2012) afirma que a educação representa, além de uma possibilidade de se efetivar sua responsabilidade social e reforçar 
seu compromisso ético com o desenvolvimento humano, uma mudança significativa no autoconceito dos idosos. Pode-se pensar em pelo menos três pontos para oferta da educação ao idoso: a dignidade, a oportunidade social e a melhoria da qualidade de vida.

O segundo ator social que vamos destacar são as instituições hospitalares ou de acolhimento de idoso, que se preocupam com a saúde biológica, psicológica e social do idoso, nesse sentido a educação oferece apoio terapêutico. Entende-se que envelhecer é a consequência de viver, sendo este linear e não necessariamente igual para todos os sistemas do corpo humano, cada um perde sua função, ou demonstra sua perda, no seu próprio ritmo, mas gradual (NORDON, 2009). Com o cérebro, o processo também se apresenta em um ritmo especial, que segundo Nordon (2009), quanto mais exigimos do nosso cérebro em atividades de raciocínio, mais ele demorará para perder suas conexões, devido à plasticidade, contudo o envelhecimento ocorre.

É comum observarmos em instituições e mesmo hospitais, a oferta de atividades voltadas as artes, mas é preciso entender que na diversidade as pessoas possuem gostos e simpatizam com atividades diferentes. Não podemos prejulgar que todo idoso se adapte ou goste de tais atividades. Temos como certo que a atividade intelectual é extremamente importante e como afirma Nordon (2009), para se evitar a perda cognitiva em idosos, certas atitudes podem ser tomadas e o estímulo contínuo da atividade cerebral, através de atividades sociais e intelectuais, além de outras, é de extrema importância.

De acordo com o Instituto Brasileiro de Geografia e Estatísticas, nas projeções etárias, seremos uma população de idosos a partir de 2030, pois estes irão superar o número de crianças. Passando a existir a necessidade de adaptação das instituições a esta demanda, assim como maior atenção aos idosos por parte destas.

No atendimento direto com o idoso, temos nosso terceiro ator social, os médicos e enfermeiros que terão o educador como parceiro de cooperação funcional. As Instituições de Longa Permanência para Idosos, ILPI, baseiam-se numa nova concepção de sistema organizacional de uma assistência multiprofissional, mas ainda conservam uma imagem negativa dos asilos, construída ao longo da história como uma assistência ao idoso, com um aspecto de caridade, de socorro aos velhos abandonados (ARAUJO et. al., 2015), e nas hospitalares há uma predominância de que além do tratamento medicinal a atividade lúdica é o suficiente para melhorar a autoestima. A inclusão do educador nessas equipes multifuncionais oferecerá uma nova atividade que coopera com a melhoria da saúde. 
É preciso pensar na estrutura do governo, e neste caso o quarto ator social, a Secretaria de Educação, SE. Nesta a inclusão da educação de jovens e adultos no Fundo de Manutenção e Desenvolvimento da Educação Básica (FUNDEB) foi um passo importante, demonstrando o empenho do Estado em estimular iniciativas para o atendimento educacional, em atenção ao Plano Nacional de Educação (BRASIL, 2014), que traz em suas diretrizes a erradicação do analfabetismo e, a população de idosos em instituições não pode e não deve ser desprezada. Assim, a educação para os idosos cooperará para consecução da meta.

O papel e a atuação dos especialistas em educação, nosso quinto ator social, já mudou há muito tempo e perdeu as características do passado. Segundo Freire (2012) se antes ele detinha "todo" conhecimento e depositava nos seus alunos aquilo que havia estudado, repassando para eles sem reflexão ou visão crítica dos conteúdos. Hoje passase a ensinar a pensar, a questionar e a aprender a ler a nossa realidade, para que possam construir opiniões próprias. Nessa nova conjectura global, à educação é atribuída a função de preparar para o exercício da democracia, constituindo uma nova fronteira para o profissional da educação (GOHN, 2011).

Embora o idoso possua uma grande experiência nas atividades laborais, encontrase, após a aposentadoria, desprezado pelo mercado de trabalho, bem como pelos mais jovens que não se interessam pelos seus conhecimentos, acreditando que o desconhecimento das novas tecnologias os tornam obsoletos. A interação com os idosos no sentido de prepará-los para continuar interagindo politicamente na sociedade é motivador e sobretudo abre novos caminhos no mercado de trabalho para o professor.

Como sexto ator social, classificamos os familiares. As relações familiares do idoso, marcam pelo afeto dedicado ao crescimento dessa família é a representação de toda a vida do idoso que foi investida até aquele momento, mas em muitos casos, observa-se o afastamento nessa relação. Segundo Mendes (2005), o ambiente familiar pode determinar as características e o comportamento do idoso. Assim, a família suficientemente sadia, em que predomina uma atmosfera saudável e harmoniosa entre as pessoas, possibilita o crescimento de todos, incluindo o idoso.

Nesse sentido, a educação irá fortalecer as relações familiares oportunizando atualização do conhecimento do idoso integrando-o aos temas atuais, despertando o interesse de relação entre a família e o idoso poderá trazer como benefício a qualidade de vida que, como afirma Bartholo et. al. (2012), é um conceito subjetivo, baseado nas percepções do indivíduo relacionadas à própria vida e ao bem estar social, que está 
fundado na satisfação, nas alegrias, nas expectativas e na felicidade percebida, estabelecendo parâmetros a partir da percepção do nível de atendimento das necessidades sociais e econômicas.

O poder político, como sendo o nosso sétimo ator social, representa o papel do Estado que assume especial relevo, tendo em vista as definições da Constituição Federal (BRASIL,1988), no Art. 1 , Parágrafo único “Todo o poder emana do povo, que o exerce por meio de representantes eleitos diretamente, nos termos desta Constituição". Cabe então ao Estado, por meio da implementação de políticas públicas, a consecução do direito à educação aos idosos.

\section{Saúde, educação e humanização}

Existem muitas escolas de educação formal, que possuem muitas carências e consideradas em número insuficiente, mas precisamos entender a relação das escolas com os hospitais. Nesse sentido, desde a década de 50 surgiram as escolas nos ambientes hospitalares e estas, expandem-se com os movimentos de direitos da criança e do adolescente e humanização nas instituições hospitalares. No Brasil, reivindicadas pelos movimentos sociais e as ações do poder público, foram criadas leis como o ECA (BRASIL, 1990) e a lei dos Direitos das Crianças e dos Adolescentes Hospitalizados (BRASIL, 2007), esta elaborada pela Sociedade Brasileira de Pediatria, SBP, e pelo Conselho Nacional dos Direitos da Criança e do Adolescente, CONANDA. Passamos, então, a ter a educação formal no hospital que recebeu a designação de Classe Hospitalar. Desenvolvem-se atividades realizadas por pedagogo apoiado pelos profissionais da saúde médicos, psicólogos e enfermeiros ativos na instituição.

Porém, apesar das escolas nos hospitais ainda possuírem uma presença muito pequena e por caracterizarem-se como um apêndice do sistema oficial de ensino, não se pode ignorar a iniciativa das Secretarias de alguns estados e municípios brasileiros, bem como de alguns hospitais que perceberam os benefícios desta atividade e preocupados procuram parcerias junto a estas Secretarias na tentativa de organizar este trabalho.

A existência das classes hospitalares são as portas para inclusão dos idosos internados à educação, pois possuem uma proposta e já ocupam um espaço nos hospitais e instituições. O idoso se encontra em uma situação muito frágil, pois no âmbito da educação está excluído, perdeu as relações com o mundo laboral, perdeu o papel de ser 
oportunizador de informações para as novas gerações, pois os avanços nas tecnologias tornam obsoletos grande parte de seus conhecimentos. Soma-se a estes, as relações com familiares, que por inúmeras contingências afastam-se do idoso. Cabe ressaltar que neste aspecto, a obrigação legal da atenção familiar ao idoso não implica em empatia, tornandose muitas vezes um horário na agenda de obrigações.

No universo das relações pessoais, Freire (2012) expressa a dialogicidade sendo a essência da educação como prática libertadora, o oprimido é segregado de seus direitos, de sua condição de cidadão, no mundo dos homens "o diálogo se impõe como caminho pelo qual os homens ganham significação enquanto homens" (FREIRE, 2012, p.85). Propiciar um espaço de diálogo ao idoso é relevante, pois oportuniza novos desafios e mesmo com todos os problemas que o envelhecimento traz, abre um espaço social e sua experiência, aliada as novas tecnologias, poderá favorecer o surgimento de novas ideias.

Existem muitas associações preocupadas com os problemas de saúde, financeiro, familiares, sociais e recreativos que permeiam o cotidiano do idoso e estas podem buscar, também, a retomada da aprendizagem, através da educação não formal, que embora o nome sugira oposição à educação formal, segundo Gohn (2011) vem se inserindo e se tornando um instrumento essencial na dialogia dos saberes, rompendo com os paradigmas tradicionais das instituições escolares, além dos conteúdos formais. Mesmo em espaços não escolares, esta é oferecida de forma diferenciada, com perspectivas de se formar o sujeito em seus mais variados aspectos. Entende-se que o importante é o diálogo, as representações meritocráticas são secundárias. Na educação não formal, existe a intencionalidade de se criar ou se buscar determinadas qualidades e/ou objetivos em espaços não escolares atuando em várias dimensões que visam à formação do indivíduo no sentido de politizar os sujeitos sobre seus direitos enquanto cidadãos, de capacitar os indivíduos para o trabalho, por meio da aprendizagem de habilidades e/ou desenvolvimento de potencialidades, de promover a aprendizagem e exercício de práticas que capacitem os indivíduos a se organizarem com objetivos comunitários, como também, o ensino-aprendizagem diferenciado dos conteúdos da escolarização formal (GOHN, 2011).

A parceria entre familiares, instituições (hospitais e asilos), escola, universidades e as organizações não-governamentais pode ser entendida como um recurso para o processo de consolidação das classes hospitalares e abrir espaços para que a educação amplie seus universos. A saúde enriquecesse com mais uma ferramenta, criando novos laços de fazer saúde para além da patologia e do envelhecimento. 


\section{Considerações finais}

As políticas públicas são um conjunto de decisões, planos, metas e ações governamentais voltadas para a resolução de problemas de interesse público, específicos ou não. Entre muitas definições sobre o que é política pública, mas a mais conhecida continua sendo a de Laswell, ou seja, decisões e análises sobre política pública implicam responder às seguintes questões: quem ganha o quê, por quê e que diferença faz (SOUZA, 2006).

Percebemos a grande necessidade de um programa de governo para a efetivação dos direitos legais do idoso, mas nesta ausência, pode-se incluir o idoso nos programas existentes. As classes hospitalares, bem como o trabalho realizado pelas organizações não-governamentais constituem a possibilidade que se apresenta nesse contexto. Entendemos que quem ganha são os idosos, a família, as instituições e o poder público, porque teremos a qualidade de vida do idoso e como diferença teremos o fim de sua exclusão social.

Programas educacionais para os idosos no Brasil precisam ser pensados e movimentos sociais de defesa do direito à educação precisam ser propostos por familiares, associações, professores, pesquisadores da área, sociedade civil e políticos. Precisamos estudar as políticas públicas e buscar sempre meios para que elas possam ser adotadas, acompanhadas e avaliadas. Precisamos propor ações urgentes para que todos tenham acesso à educação de qualidade.

O presente artigo teve por escopo contribuir para o debate sobre a elaboração de novas políticas públicas voltadas ao idoso, especificamente, no aproveitamento das classes hospitalares. Esse modelo de estruturas elementares, proposto por Di Giovani, como instrumento para se analisar as políticas públicas voltadas ao idoso e à educação, principalmente, à educação inclusiva, possibilitou vermos nesse conjunto de políticas, leis e regras a viabilidade de formulação de uma política pública voltada à educação do idoso em internação, como forma de reinclusão social e contribuir para melhoria da qualidade de vida destes.

\section{REFERÊNCIAS}


ARAÚJO, Rayane Kelly de Lima.; DENISE, Sousa Moreira.; XAVIER, Renata Carla Torres.; PEIXOTO, Berenguer de Souza. Atividades lúdicas com idosos institucionalizados: um relato de experiência. Revista Saúde e Ciência, on line, v.4, n.3. Suplemento dezembro de 2015, p. 89-93. Disponível em: $<$ http://150.165.111.246/revistasaudeeciencia/index.php/RSC-

UFCG/article/viewFile/305/221\#page=90>. Acesso em: 22 maio 2016.

BARTHOLO, Maria Elisa Carvalho.; ROCHA, Fátima Niemayer.; LIMA, Bárbara Dana.; PACHECO, Luara de Freitas. Educação e qualidade de vida do idoso: uma ação de extensão no centro de convivência do idoso. Revista Fluminense de Extensão Universitária, Vassouras, V. 2, N. 1, p. 21-32, jan/jun., 2012. Disponível em: <http://editorauss.uss.br/index.php/RFEU/article/view/399>. Acesso em: 22 maio 2016.

BRASIL. Estatuto da Criança e do Adolescente, Lei no 8.069, de 13 de julho de 1990. Disponível em <http://www.planalto.gov.br/ccivil_03/LEIS/L8069.htm>. Acesso em: 13 set. 2015.

BRASIL. Conselho Nacional dos Direitos da Criança e do Adolescente. Direitos da Criança e do Adolescente Hospitalizada. Resolução no 41 de outubro de 1995. Diário Oficial da União, 17/10/95 - Seção I, p.163/9-16320 - Brasília - Distrito Federal

BRASIL. Estatuto do Idoso. Lei $\mathbf{n}^{\mathbf{0} 10.741}$, de $1^{\text {o }}$ de outubro de 2003. Disponível em: <http://www.planalto.gov.br/ccivil_03/leis/2003/L10.741.htm>. Acesso em: 15 maio 2016.

BRASIL. Lei no 13.005, Plano Nacional de Educação, de 25 de junho de 2014. Disponível em: <http://www.planalto.gov.br/ccivil_03/_ato2011-2014/2014/lei/113005.htm>. Acesso em: 13 set. 2015.

BRASIL. Ministério do Planejamento, Desenvolvimento e Gestão. O que é orçamento público. Disponível em: <http://www.planejamento.gov.br/servicos/faq/orcamento-dauniao/conceitos-sobre-orcamento/o-que-e-orcamento-publico>. Acesso em: 23 maio 2016.

CARVALHO, Fagner dos Santos. O Papel dos Grupos de Interesse e Pressão na Formatação e Fortalecimento da Democracia Brasileira: O Caso do Departamento Intersindical Assessoria Parlamentar (Diap) Durante o Processo da Constituinte (1987/1988) Brasileira. AURORA, ano III número 5, dezembro de 2009. Disponível em: <http://www.marilia.unesp.br/Home/RevistasEletronicas/Aurora/CARVALHO.pdf> Acesso em: 12 fev. 2016.

DI GIOVANNI, Geraldo. As Estruturas Elementares das Políticas Públicas. Caderno de pesquisa, $\quad$ v. $2009 . \quad$ Disponível em: $<$ https://observatorio03.files.wordpress.com/2010/06/elementos-das-politicaspublicas.pdf >. Acesso 15 maio 2016.

FREIRE, Paulo. Pedagogia do oprimido. Ed. Especial, Rio de janeiro, Nova Fronteira, 2012. 
GOHN, Maria da Glória. Educação-não formal e cultura política: impactos sobre o associativismo do terceiro setor. 5. Ed; São Paulo; Cortez, 2011.

IBGE. Instituto Brasileiro de Geografia e Estatística. Projeção da população por sexo e idade: Brasil 2000-2060. Unidades da Federação 2000-2030, 29 de agosto de 2013. Disponível em: <Projeção da população por sexo e idade: Brasil 2000-2060 Unidades da Federação 2000-2030>. Acesso em: 15 maio 2016.

IBGE. Instituto Brasileiro de Geografia e Estatística. Distribuição da população por sexo, segundo os grupos de idade. Brasil, 2000 e 2010. Disponível em <http://censo2010.ibge.gov.br/sinopse/webservice/frm_piramide.php?ano=2000\&codig $\mathrm{o}=\&$ corhomem $=88 \mathrm{C} 2 \mathrm{E} 6 \&$ cormulher $=\mathrm{F} 9 \mathrm{C} 189 \&$ wmaxbarra $=180>$. Acesso em: 15 maio 2016.

MANTOAN, Maria Teresa Eglér. Inclusão Escolar: o que é? por quê? como fazer? São Paulo: SUMMUS, 2015.

MENDES, Márcia R. S. S. Barbosa.; GUSMAO, Josiane Lima de.; FARO, Ana Cristina Mancussi.; LEITE, Rita de Cássia Burgos de O. A situação social do idoso no Brasil: uma breve consideração. Acta paul. enferm. [on line]. 2005, vol.18, n.4, pp.422-426. Disponível em: <http://dx.doi.org/10.1590/S0103-21002005000400011>. Acesso em: 31 maio 2016.

MINAYO, Maria Cecília de Souza.; HARTZ, Zulmira Maria de Araújo.; BUSS, Paulo Marchiori. Qualidade de vida e saúde: um debate necessário. Ciência e Saúde Coletiva, v. $5, \quad$ n. $1, \quad$ p. 7-18, 2000. Disponível em: <http://adm.online.unip.br/img_ead_dp/35428.PDF>. Acesso em: 07 jun. 2016.

NORDON, D., GUIMARÃES, R., KOZONOE, D., MANCILHA, V., NETO, V.. Perda cognitiva em idosos. Revista da Faculdade de Ciências Médicas de Sorocaba. 11 de set. 2009.2 Disponível em: <http://revistas.pucsp.br/index.php/RFCMS/article/view/1874/1288>. Acesso em: 25 maio 2016.

PERUZZO, Cecilia Maria Krohling. Representações dos movimentos populares na mídia e como eles se representam: visibilidade pública e perspectivas cívicas. Conexão Comunicação e Cultura, UCS, Caxias do Sul - v. 14, n. 28, jul./dez. 2015, p. 31-49. Disponível em: <http://www.ucs.br/etc/revistas/index.php/conexao/article/viewFile/3874/2329> Acesso em: 22 fev. 2016.

SÃO PAULO, Secretaria de Educação. Mundo do Trabalho. Disponível em: <http://www.ejamundodotrabalho.sp.gov.br/oqueE.aspx>. Acesso em: 15 maio 2016

SOARES, Marcia Regina Pacheco.; ISTOE, Rosalee Santos Crespo. Alfabetização e inclusão de pessoas idosas: uma proposta interdisciplinar mediada pelas tecnologias da informação e da comunicação. Revista Científica Interdisciplinar. V. 2, n. 3, p. 165424, jul./set. 2015. Disponível em: <http://revista.srvroot.com/linkscienceplace/index.php/linkscienceplace/article/view/12 3/62>. Acesso em: 15 maio 2016. 
SOUZA, Celina. Políticas Públicas: Uma Revisão da Literatura. Sociologias, Porto Alegre, ano 8, $\mathrm{n}^{\mathrm{o}} 16$, jul/dez 2006, p. 20-45. Disponível em: <http://www.scielo.br/pdf/soc/n16/a03n16>. Acesso em: 14 fev. 2016.

\section{Como referenciar este artigo}

TELLES JÚNIOR, Hamilton de Oliveira et al. Políticas públicas de direito à educação para os idosos em internação. Revista on line de Política e Gestão Educacional, Araraquara, v.21, n.2, p. 393-408, maio-ago. 2017. Disponível em: <http://dx.doi.org/10.22633/rpge.v21.n.2.2017.10025>. ISSN: 1519-9029.

Submetido em: 30/05/2017

Aprovado em: 20/06/2017 